\title{
8
}
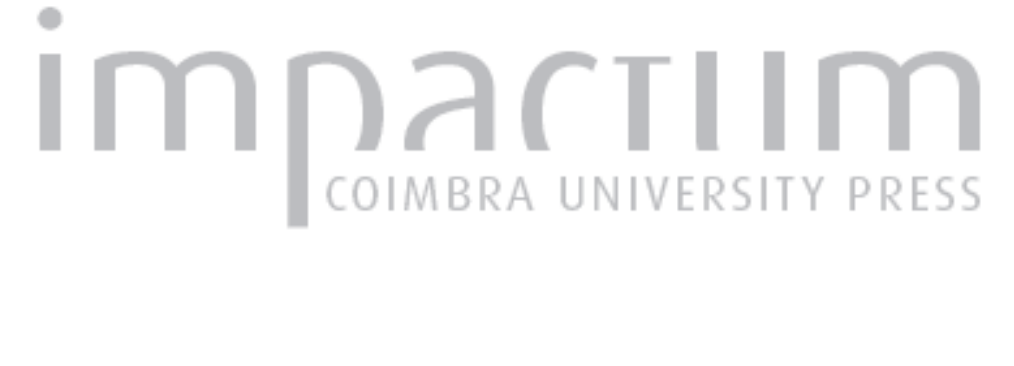

Epigrafia, tempos e memórias: homenagem a José d'Encarnação

Autor(es): $\quad$ Lopes, Maria da Conceição; Carvalho, Pedro C.; Redentor, Armando

Publicado por: Faculdade de Letras da Universidade de Coimbra/Imprensa da

Universidade de Coimbra

URL

persistente:

URI:http://hdl.handle.net/10316.2/41865

DOI:

DOI:https://doi.org/10.14195/1647-8657_55_2

Accessed : $\quad$ 26-Apr-2023 11:31:39

A navegação consulta e descarregamento dos títulos inseridos nas Bibliotecas Digitais UC Digitalis, UC Pombalina e UC Impactum, pressupõem a aceitação plena e sem reservas dos Termos e Condições de Uso destas Bibliotecas Digitais, disponíveis em https://digitalis.uc.pt/pt-pt/termos.

Conforme exposto nos referidos Termos e Condições de Uso, o descarregamento de títulos de acesso restrito requer uma licença válida de autorização devendo o utilizador aceder ao(s) documento(s) a partir de um endereço de IP da instituição detentora da supramencionada licença.

Ao utilizador é apenas permitido o descarregamento para uso pessoal, pelo que o emprego do(s) título(s) descarregado(s) para outro fim, designadamente comercial, carece de autorização do respetivo autor ou editor da obra.

Na medida em que todas as obras da UC Digitalis se encontram protegidas pelo Código do Direito de Autor e Direitos Conexos e demais legislação aplicável, toda a cópia, parcial ou total, deste documento, nos casos em que é legalmente admitida, deverá conter ou fazer-se acompanhar por este aviso. 
CONIMBRIGA

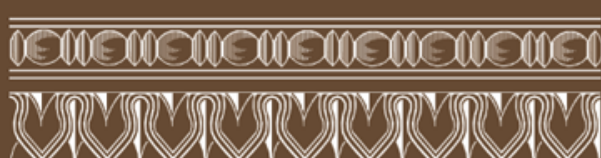

INSTITUTO DE ARQUEOLOGIA

VOLUME LV • 2016

FACULDADE DE LETRAS
UNIVERSIDADE DE COIMBRA 


\section{EPIGRAFIA, TEMPOS E MEMÓRIAS: HOMENAGEM A JOSÉ D'ENCARNAÇÃO}

https://doi.org/10.14195/1647-8657_55_2

Epigrafia, Tempos e Memórias foi o mote de uma singular jornada de homenagem ao Professor Doutor José d'Encarnação que, a 28 de outubro de 2015, aconteceu na Faculdade de Letras da Universidade de Coimbra (FLUC).

O processo que gerou o evento dimanou da reunião de vontades dos signatários, mas integrou-se num corpo mais vasto correspondente à FLUC, nomeadamente à sua estrutura orgânica da área das ciências históricas - em particular, o Departamento de História, Estudos Europeus, Arqueologia e Artes (DHEEAA) e a secção de Arqueologia/ Instituto de Arqueologia - a par da unidade de investigação na qual se filia boa parte dos ativos humanos do âmbito da Arqueologia e das Artes desta Faculdade, o Centro de Estudos de Arqueologia, Artes e Ciências do Património (CEAACP). Esta instituição de I\&D integra, entre os investigadores mais proeminentes que a compõem, o Professor Doutor José d'Encarnação, que, apesar de aposentado desde 2007, com ela mantém, bem como genericamente com a FLUC, uma relação fecunda, por via do suporte a projectos e iniciativas a que continua a dedicar o seu saber.

Tendo sido uma jornada de tributo à sua ação, ao seu legado, ao seu papel de professor e de investigador, a mesma recebe, agora, anunciado desenlace, pela publicação deste número da revista Conimbriga que é inteiramente dedicado ao homenageado, reunindo um conjunto de contributos que vão ao encontro do perfil do homem comprometido com o tempo em que vive e com a ciência.

É consabido que a figura ímpar do Professor Doutor José d'Encar- 
nação vem marcando gerações de alunos na FLUC, granjeando notável posição entre os seus pares e filiando diversíssimos públicos. Consequentemente, três ordens de razões justificativas devem ser evocadas para esta ação de tributo que se vem levando a cabo: a primeira inscreve-se, naturalmente, numa dimensão institucional; a segunda, prende-se com a dimensão pedagógica e científica do homenageado; a terceira, centra-se na sua dimensão humana.

O Professor Doutor José d'Encarnação chega à FLUC em 1976, como assistente, tornando-se professor auxiliar em 1984, na sequência do seu Doutoramento em História, com a reconhecidíssima tese Inscrições Romanas do Conventus Pacensis. Dois anos depois, ascende a professor associado, tornando-se catedrático em 1991.

Ao longo de três décadas, desempenha diversos cargos de gestão na vida interna da FLUC, como a presidência do Conselho Pedagógico ou da Comissão Científica do Grupo de História, ou a direcção do Instituto de Arqueologia; mas são também de ressaltar as responsabilidades de coordenação do Programa SÓCRATES/ERASMUS, que exerceu no contexto do Grupo de História, e, ainda, de delegado do Conselho Directivo da Faculdade para a supervisão das diferentes áreas deste programa.

A expressão científica da sua carreira garantiu-lhe representação no associativismo científico internacional, destacando-se, por exemplo, a integração, por mais de uma vez, no comité da Association Internationale d'Épigraphie Grecque et Latine, e a pertença aos órgãos de mais de uma vintena de revistas científicas nacionais e internacionais.

Poder-se-á, ainda, invocar uma intensa actividade de cidadania exercida em contexto associativo e autárquico, nomeadamente ligada ao município de Cascais - onde reside - e freguesias afectas. Por isso mesmo, foi agraciado com a medalha de mérito municipal de Cascais (1994) e recebeu, do Rotary Club de Cascais-Estoril, o diploma de Mérito Profissional Rotário (2000).

A sua dimensão pedagógica tende a cristalizar-se na imagem do professor de Epigrafia e História Antiga, cadeiras que assiduamente leccionou na FLUC, ainda que outras tivesse também tido a seu cargo, nomeadamente no âmbito da comunicação social e do património cultural ou, especificamente, arqueológico.

Os dotes comunicacionais que se lhe reconhecem são marca indissociável da competência pedagógica que gerações de estudantes vêem atestando, mas também outros públicos, sejam eles nichos científicos 
ou assembleias mais indiferenciadas. E esta capacidade em muito beneficiará da prática da actividade jornalística na rádio e em diferentes publicações locais, que, em continuidade, vem desenvolvendo.

Em termos científicos, é de salientar uma produção bibliográfica que, entre artigos, capítulos de obras colectivas e livros, ultrapassa largamente as oito centenas de títulos.

De sua iniciativa é a criação do Ficheiro Epigráfico (1982), uma publicação de referência exclusivamente dedicada às novas descobertas no âmbito das inscrições romanas, concebida como suplemento à revista Conimbriga e que continua com dinâmica assinalável. Esta é senha identitária da escola coimbrã de Epigrafia que o Professor Doutor José d'Encarnação bem soube potenciar e internacionalizar, constituindo-se numa mais-valia incontornável para a Universidade de Coimbra, que importa continuar estruturalmente a cuidar, para que não definhe enredada em lógicas conjunturais de política educativa ou de financiamento da Ciência.

O reconhecimento internacional da sua ampla actividade científica desenvolvida, sobretudo, a partir de Coimbra, valeu-lhe tornar-se Académico Correspondente da Reial Acadèmia de Bones Lletres de Barcelona (1997) e da Real Academia de la Historia (1999), bem como a atribuição do Doutoramento honoris causa pela Universidade de Poitiers (2001). Em Portugal, ascendeu a Académico de Mérito da Academia Portuguesa de História (2010) e, muito recentemente, a membro-correspondente da $4^{\text {a }}$ Secção (História e Geografia) da Academia das Ciências de Lisboa (2016).

A esta consagração nos planos nacional e internacional não são alheias as suas qualidades humanas, a sua simpática disposição, o seu humor subtil, a sua comunicação chã, que lhe têm granjeado uma enorme plêiade de amigos espalhados pelas principais instituições universitárias europeias - com destaque para as de Espanha, França e Itália -, sul americanas - mormente do Brasil - e portuguesas. E é certo que, em regra, os interesses científicos acabam por ser cimentados por fraterno entendimento, como apraz registar sempre há o privilégio de coincidir com ele em qualquer reunião científica, dentro ou fora do país, ou evento cultural. Mas essa dimensão humana é também confirmada por amigos e colegas mais próximos, pelas gerações de alunos que marcou das mais diversas formas, pelo modo como se amoldou a este mundo cada vez mais globalizado e cibernético, procurando, também, no ciberespaço, registar essa dimensão de humanismo. 
Reconhecidos pelo testemunho inspirador do Professor Doutor José d'Encarnação, primeiro enquanto discentes, depois como colegas e amigos, damos prosseguimento, juntamente com os autores que colaboram neste volume, ao singelo tributo a esta personalidade singular que meritoriamente avulta nas áreas científicas a que se tem devotado, desejando que prossiga no acompanhamento inteligente, rigoroso e interventivo dessas e doutras matérias do seu interesse e em exercício de cidadania.

O presente número da Conimbriga reúne um conjunto de catorze artigos, maioritariamente de índole epigráfica. Nuns focam-se aspectos teóricos e metodológicos da disciplina, noutros apresentam-se estudos, quer atinentes ao âmbito hispânico, quer ao extrapeninsular, acerca de inscrições concretas - inclusive inéditas -, sobre hábito e conjuntos epigráficos, prosopografia e onomástica. Arqueologia e ideologia concitam também reflexão. E, com propriedade, os caminhos da investigação percorridos pelo homenageado são outro dos assuntos que dão corpo às páginas sequentes, nas quais se esboça um périplo temático que une as províncias hispânicas com paragens além-pirenaicas, designadamente gálicas e itálicas, sob o signo de Roma.

Maria da Conceição LOPES

Pedro C. CARvalho

Armando REDENTOR 